\title{
Sulfonated Pyromellitic Dianhydride-functionalized MCM-41: A Multifunctional Hybrid Catalyst for Melting-assisted Solvent-free Synthesis of Bioactive 3,4-dihydropyrimidin-2-(1H)-ones
}

\author{
Ehsan Valiey \\ Iran University of Science and Technology \\ Mohammad Dekamin ( $\nabla$ mdekamin@iust.ac.ir) \\ Iran University of Science and Technology \\ Zahra Alirezvani \\ Iran University of Science and Technology
}

\section{Research Article}

Keywords: Hybrid organosilica, Solid acids, Pyromellitic dianhydride, Biginelli reaction, Green chemistry

Posted Date: January 18th, 2021

DOI: https://doi.org/10.21203/rs.3.rs-145252/v1

License: (c) (i) This work is licensed under a Creative Commons Attribution 4.0 International License.

Read Full License 


\section{Abstract}

This study introduces a practical approach to fabricate a novel hybrid catalyst of namely sulfonated pyromellitic dianhydride-aminopropyl silane-functionalized MCM-41 (MCM-41-APS-PMDA-SO $\left.{ }_{3} \mathrm{H}\right)$. Various microscopic, spectroscopic methods and techniques such as FTIR, TGA, XRD, FESEM, and EDX were used to confirm its structural characteristics. The efficiency of the new MCM-41-APS-PMDA-SO ${ }_{3} \mathrm{H}$ organosilica nanomaterials, as a heterogenous nanocatalyst, was evaluated in promoting the synthesis of biologically active 3,4-dihydropyrimidin-2-(1H)-one derivatives under solvent-free conditions. It is not only a nanoporous material for enriching reactants with high surface area provided, but also possesses great acidic sites to activate carbonyl groups. Furthermore, favored reusability of the new introduced hybrid organosilica with negligible loss of its activity, easy and quick isolation of the products are the main advantages of this procedure.

\section{Introduction}

In recent decades, the synthesis and use of mesoporous structures have received much attention. The M41S family consists mainly of silica, $\mathrm{SiO}_{2}$. Silica has certain advantages as support like high chemical and thermal stability, has a large number of silanol $(\mathrm{Si}-\mathrm{OH})$ groups and simplicity of operation. MCM-41 became the most attractive member of the M41S family due to with ordered structure and its special properties such as exceptionally high surface area $\left(>1000 \mathrm{~m}^{2} \mathrm{~g}^{-1}\right)$, narrow pore-size distribution (1.5$10 \mathrm{~nm}$ ), and having a hexagonal arrays of cylindrical mesopores ${ }^{1-4}$. These properties have made MCM41 known as a support for of metal oxides ${ }^{5}$, heteropoly acids ${ }^{6}$, complexes $^{7}$, drug delivery systems ${ }^{8-12}$, candidate for sensors ${ }^{13}$, degradation inhibitor in polymer dielectrics ${ }^{14}$, adsorption of organic pollutants ${ }^{15}$, and solid supports to immobilize catalysts ${ }^{16-19}$. However, the acid strength of the pure MCM-41 is relatively weak, which hinders its catalysis applications. Modification of its surface can lead to the formation of a solid acid with high uniformity, which is regularly modified by covalent anchoring of various organic particles in a mesoporous material or replacing of $\mathrm{Si}$ atoms by other tetra-, tri- and divalent metals such as $\mathrm{Al}, \mathrm{B}, \mathrm{Fe}, \mathrm{Mn}, \mathrm{Zn}$, etc ${ }^{10,20-35}$. It is expected that the use of MCM-41 as catalyst support for the sulfonated pyromellitic dianhydride may greatly enhance the catalytic capabilities of designed catalyst components.

During the last few years, solvent-free organic synthesis (SFOS) of biologically activated molecules has been an effective tool for the rapid generation of various compound collections. In fact, the SFOS obviously include the formation of a liquid phase reaction. This melting mentions the eutectic mixture with temperature fusion below the melting points of the reactants. These solvent-free protocols have the advantage of including the following: the products are sufficiently pure which does not require further purification or recrystallization; the reactions are sometimes rapid as compared to using solvent conditions; functional group protection-deprotection can be avoided and sometimes the use of solventfree conditions is more affordable $e^{36,37}$. Furthermore, the use of multicomponent reactions (MCRs) allow to achieved maximum diversity molecules in a single and simple synthetic procedure ${ }^{38-41}$. The synthesis 
of high-value chemical compounds to produce a library of small molecules enhances the concerted growth of solvent-free and MCRs as a significant too ${ }^{42}$.

In past few decades, dihydropyrimidinones (DHPMs) and their derivatives, an important class of heterocycle compounds, have stimulated interest in medicinal chemistry due to diverse biological activity ${ }^{43-45}$. Heterocycle compounds containing pyrimidine moiety in the ring nucleus have a significant presence in natural products such as vitamin $B_{1}$ and synthetic organic compounds, such as barbituric acid and veranal which are used as hypnotics ${ }^{46}$. Several methods have been developed for the synthesis of DHPMs ${ }^{47}$. A considerable type of catalysts to date have been reported to promote classical synthesis of DHPMs by Biginelli reaction in an elegant manner ${ }^{48-50}$. Among these catalysts system, immobilized catalyst moiety onto the large area surface of solid polymeric supports, in particular silica can improve the synthetic procedure ${ }^{51-54}$. In continuation of our ongoing efforts towards expanding efficient and novel heterogeneous catalysts for different MCRs ${ }^{55-60}$. We wish herein to introduce, preparation and characterization of the new hybrid nano-catalyst of an organic-inorganic framework sulfonated pyromellitic dianhydride-aminopropyl silane-functionalized MCM-41 (MCM-41-APS-PMDA-SO $\left.{ }_{3} \mathrm{H}\right)$ and investigative of its catalytic activity for the from a variety of substrates from aromatic aldehydes, ethyl acetoacetate and urea to afford the corresponding Biginelli 3,4-dihydropyrimidin-2-(1H)-one derivatives (Scheme 1). To the best of our knowledge, there is not any report for the use of sulfonated pyromellitic dianhydride grafted on the surface of MCM- 41 as a heterogeneous nano-catalyst, for different MCRs including Biginelli 3,4-dihydropyrimidin-2-(1H)-one derivatives.

\section{Results And Discussion}

The prepared MCM-41-APS-PMDA-SO ${ }_{3} \mathrm{H}$ nanomaterial was analyzed by FT-IR, XRD, FESEM, EDX and TGA analysis. The FT-IR spectra of MCM-41 (a), MCM-41-APS (b) MCM-41-APS-PMDA (c) and MCM-41-APSPMDA-SO ${ }_{3} \mathrm{H}$ have been compared in Fig. 1. The nano ordered MCM-41 showed a band in the area of $3443 \mathrm{~cm}^{-1}$ which is due to the $\mathrm{OH}$ of $\mathrm{Si}-\mathrm{OH}$ and adsorbed water molecules on the surface (Fig. 1a) ${ }^{61}$. The band due to $\mathrm{Si}-\mathrm{O}-\mathrm{Si}$ for MCM-41 and all subsequent added layers are observed around 1062$1228 \mathrm{~cm}^{-1}$. The signals appeared around $1600 \mathrm{~cm}^{-1}$ and $2883 \mathrm{~cm}^{-1}$ are attributed to the symmetric bending vibration of $\mathrm{NH}_{2}$ and aliphatic $\mathrm{C}-\mathrm{H}$ stretching of 3-APTES, respectively (Fig. $1 \mathrm{~b}$ ). These observed characteristic bands and decrease intensity of $\mathrm{OH}$ bond of MCM-41 surface confirms that MCM-41 substrate covalently modified by linker. Moreover, the signals appeared at around 2923-3604, 1716 and $1569 \mathrm{~cm}^{-1}$ are attributed to the stretching vibrations of the pyromellitic dianhydride (Fig. 1c). Also, the special peaks at $1228 \mathrm{~cm}^{-1}$ are assigned to the $S=0$ stretching vibration of the $\mathrm{SO} 3 \mathrm{H}$ group (Fig. $1 \mathrm{~d}$ ).

The morphology and tissue structure of MCM-41and MCM-41-APS-PMDA-SO3H (1) were examined using field emission scanning electron microscopy (FESEM). As shown in Fig. 2, the morphological distinction between the pure MCM-41 (a,b and c images) and MCM-41-APS-PMDA-SO ${ }_{3} \mathrm{H}(1)$ (d,e and $\mathrm{fimages}$ ) are a 
very important proof of the immobilization of the sulfonated pyromellitic dianhydride-aminopropyl silane complex on the external surface of the MCM-41 matrix.

The thermogravimetric analysis (TGA) of the MCM-41-APS-PMDA-SO ${ }_{3} \mathrm{H}(1)$ are shown in Fig. 3. The TGA curve of MCM-41-APS-PMDA-SO ${ }_{3} \mathrm{H}$ shows three steps of weight loss. In the first step, $10 \%$ weight loss between room temperature and $150{ }^{\circ} \mathrm{C}$ belongs to absorbed water held in the pores of nanomaterial. While the second weight loss between $150-350^{\circ} \mathrm{C}$ is due to decomposition of the organically modified framework. Also, the third weight loss $(17 \%)$ between $380-600{ }^{\circ} \mathrm{C}$ was related to decomposition of silanol groups. These results also indicate that pyromellitic dianhydride has been conjuncted onto the surface of MCM-41.

As shown in Fig. 4, the EDX analysis of the MCM-41-APS-PMDA-SO ${ }_{3} \mathrm{H}(1)$ verified the presence of $\mathrm{Si}$ (11.61\%), C (14.89\%), O (57.63\%), N (12.90\%), and S (2.98\%), respectively.

The powder XRD pattern of MCM-41 (Fig. 5, part a) shows low angle reflections of (d100), (d110) and (d200) at $2 \theta=2.77,4.67$ and 5.13 , respectively. These plates confirm the formation of mesoporous with hexagonal structure of pore particles and regular, a marker of MCM-41 of type mesoporous. Furthermore, other peaks of the XRD pattern can be belongs to other components of components of nanocatalyst in the wide angle area. The diffraction signals $(2 \theta)$ at $14^{\circ}, 19^{\circ}, 23^{\circ}, 25^{\circ}, 26^{\circ}, 29.28^{\circ}$ illustrates the formation of MCM-41-APTES-PMDA-SO ${ }_{3} \mathrm{H}$ (Fig. 5, part b).

Figure 6 demonstrates the $\mathrm{N}_{2}$ adsorption/desorption isotherms related to MCM-41, MCM-41-APS-PMDA$\mathrm{SO}_{3} \mathrm{H}$. Isotherm type $\mathrm{V}$ was recognizable for MCM-41 with hysteresis. In fact, grafting of $\mathrm{PMDA}^{-\mathrm{SO}_{3} \mathrm{H}}$ groups through (3-aminopropyl) triethoxysilane linker onto the surface of MCM-41 can close them, cause to broad pore distribution and the decrement of the surface. The table shows the parameters such as pore volume as well as average pore diameter in MCM-41 and synthesized nanocomposite

Figure 6. Adsorption/desorption isotherm of the MCM-41-APS-PMDA-SO ${ }_{3} \mathrm{H}$ (1).

\section{General procedure for the synthesis of 3,4- dihydropyrimidinones catalyzed by the MCM-41-APS- PMDA-SO ${ }_{3} \mathrm{H}(1)$}

To evaluate the effect of the MCM-41-APS-PMDA-SO ${ }_{3} \mathrm{H}(\mathbf{1})$ as an introduced catalyst under different reaction conditions, the reaction of ethyl acetoacetate $(2,1 \mathrm{mmol})$, 4-chlorobenzaldehyde (3a, $1 \mathrm{mmol})$ and urea $(4,1.2 \mathrm{mmol})$ was investigated as the model reaction to afford 3,4-dihydropyrimidin-2(1H)-ones. The systematic reaction parameters like solvent, catalyst loading and temperature were optimized. The results are summarized in Table 1. The results of using different protic and aprotic solvents showed that the reaction in solvent-free conditions at $80 \otimes C$ proceeded with acceptable efficiency ( $95 \%$ yield) in 35 min, which encouraged us to perform this reaction in solvent-free conditions (Table 1, entry 11). 
Remarkably, the model reaction was investigated in the presence of $15 \mathrm{mg}$ of catalyst 1 in solvent-free conditions at $80^{\circ} \mathrm{C}$, the favorable product was gained with quantitative efficiency (Entry 11).

Subsequently, by further reducing the amount of catalyst, a lower yield of the favorable product was gained under similar conditions even in over a longer time. To our delight, it was found that $15 \mathrm{mg}$ of

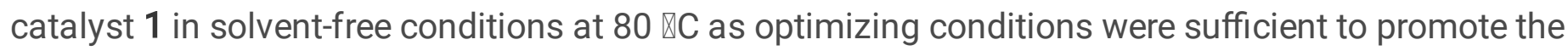
model reaction efficiently. Indeed, the results strongly confirmed the role of MCM-41-APS-PMDA-SO ${ }_{3} \mathrm{H}(1)$ to promote the synthesis of 3,4-dihydropyrimidin-2(1H)-ones. Therefore, optimized conditions have been developed using different aromatic aldehydes to synthesize other derivatives of favorable products $\mathbf{5}$. The results are given in Table 2 .

Noticeably, the desired products were gained in high to excellent yields. Actually, electron-withdrawing groups of the aromatic ring of aldehydes $\mathbf{3}$ generally react faster compared to the electron-donating groups. These results clearly confirm the suitable catalytic activity of the MCM-41-APS-PMDA-SO3H (1) hybrid nanomaterials to promote the biginelli condensation of a wide range of aldehydes with ethyl acetoacetate and urea. According to above standpoints, the following mechanism can be proposed for the synthesis of 3,4-dihydropyrimidin-2(1H)-ones synthesis condensation (Scheme 3). First, MCM-41APTES-PMDA-SO ${ }_{3} \mathrm{H}$ (1) activates the carbonyl functional group of aromatic aldehydes $\mathbf{3}$ followed by addition of urea $\mathbf{4}$ forming intermediate (I). Followed by dehydration, to form the corresponding imminium intermediate (II) from an equivalent of urea $\mathbf{4}$ and aromatic aldehydes $\mathbf{3}$. Subsequent addition of the ethyl acetoacetate compound forming intermediate (III), followed by cyclization and dehydration, would afford the 3,4-dihydropyrimidinone $\mathbf{5}$.

After completing the reaction, the introduced catalyst was separated, washed several times, and dried then reused in the reaction without any reduction inactivity. The catalyst was used for four cycles in reaction with very little activity reduction (approx. 10\%). The results are shown in Fig. 6.

To illustrate the catalytic activity of the new MCM-41-APS-PMDA-SO ${ }_{3} \mathrm{H}$ organosilica nanomaterials as a heterogenous nanocatalyst, its efficiency has been compared with some of the previously reported catalysts for the preparation of $\mathbf{5 a}$ (Table 3). The results illustrate that this study is actually superior to other cases in terms of reaction time, product performance, amount of catalyst, non-toxicity, non-use of intermediate and expensive transition metals, and the obtained efficiency for the catalyst recycling.

\section{Experimental Section}

\section{General Information}

All chemicals are purchased from Merck or Aldrich. Melting points were specified using an Electrothermal 9100 device and are unmodified. Characterization of new hybrid nanocatalyst 1 was performed by FESEM TESCAN-MIRA3, EDX Numerix DXP-X10P, Shimadzu FT-IR-8400S and TGA Bahr Company STA 504. The XRD pattern of the catalyst was obtained using TW 1800 diffractometer with Cu Ka radiation ( $\lambda$ $=1.54050 \AA$ ). . The analytical thin layer chromatography (TLC) experiments was performed using Merck 
$0.2 \mathrm{~mm}$ silica gel 60F-254Al-plates. All compounds well characterized by IR and ${ }^{1} \mathrm{H} \mathrm{NMR}(500 \mathrm{MHz}$, Bruker DRX-500 Avance spectrometers in DMSO).

General procedure for preparation of the MCM- 41 Nano ordered mesoporous silica MCM- 41 were prepared by hydrothermal synthesis conforming to the known method. ${ }^{33} .2 .70 \mathrm{~g}$ of diethyl amine was dissolved in $42 \mathrm{~mL}$ deionized water at room temperature. The mixture was stirred for $10 \mathrm{~min}$, then $1.47 \mathrm{~g}$ of cetyltrimethylammonium bromide (CTAB) was added and the surfactant solution was stirred for 30 min until a clear solution was gained. Next, $2.10 \mathrm{~g}$ tetraethyl orthosilicate (TEOS) was gently added and by drop wise addition of $\mathrm{HCl}$ solution $(1 \mathrm{M})$, the $\mathrm{pH}$ of the mixture was fixed at 8.5 to gain the final precipitate. The resulting mixture was stirred for $2 \mathrm{~h}$, next the resulting white precipitate was filtered and washed with $100 \mathrm{ml}$ of water. Then it was dried at $45^{\circ} \mathrm{C}$ for $12 \mathrm{~h}$ and finally, the sample was calcined at $550{ }^{\circ} \mathrm{C}$ with the rate of $2{ }^{\circ} \mathrm{C} / \mathrm{min}$ for $5 \mathrm{~h}$.

General procedure for preparation of the MCM-41-APS-PMDA-SO ${ }_{3} \mathrm{H}(1)$ In a 200-mL round button flask, (3-aminopropyl) triethoxysilane $0.15 \mathrm{mmol}, \mathrm{d}=0.946 \mathrm{~g} / \mathrm{mL}$ ) was added to a $0.15 \mathrm{~g} \mathrm{MCM}-41$ in $15 \mathrm{~mL}$ dry toluene. After $8 \mathrm{~h}$, the residue white solid MCM-41-(SiCH2CH2CH2NH2) , was filtered, and washed with toluene and chloroform several times to remove any excess of linker. Then, dried solid was dehydrated at $120 \otimes C$ for $1 \mathrm{~h}$ under nitrogen atmosphere Next, $0.15 \mathrm{~g}$ white solids and $0.15 \mathrm{~g}$ of pyromellitic dianhydride were disperse in dry THF $(30 \mathrm{ml})$ for $1 \mathrm{~h}$. Following this, $0.10 \mathrm{~g}$ of triethylamine (TEA) was added to the obtained mixture. The mixture was stirred at room temperature for $24 \mathrm{~h}$, under inert atmosphere. Then, the obtained solid was filtered off and washed with toluene and EtOH for several times, respectively. For sulfonation of prepare solid, $0.10 \mathrm{~g}$ of triethylamine was added to $0.10 \mathrm{~g}$ of sulfamic acid and stirred for $1 \mathrm{~h}$. Following, the obtained solid dissolved in dry toluene $(20 \mathrm{~mL})$ and added to the sulfamic acid solution. The mixture was stirred at reflux condition for 36 under inert atmosphere. Finally, the residues were filtered, washed several times and dried in vacuum drying oven at $60 \mathrm{oC}$ for $8 \mathrm{~h}$. The preparation schematic route of the MCM-41-APS-PMDA-SO3H (1) has been shown in Scheme 1.

General procedure for the synthesis of 3,4-dihydropyrimidinones catalyzed by the MCM-41-APS-PMDA-SO ${ }_{3} \mathrm{H}(1)$ In a $5 \mathrm{~mL}$ round-bottom flask, a mixture of ethyl acetoacetate $(2,1 \mathrm{mmol})$, aldehydes $(3,1 \mathrm{mmol})$, urea $(4,1.2 \mathrm{mmol})$ and MCM-41-APS-PMDA-SO ${ }_{3} \mathrm{H}(1,15 \mathrm{mg})$ were heated to 80 खC under solvent-free conditions for times indicated in Table 2. The advance of the reactions was checked out by TLC (Eluent: EtOAc: $n$-hexane, 1:3). At the end of the reaction, $96 \% \mathrm{EtOH}(5 \mathrm{~mL})$ was added to the mixture. The heterogeneous catalyst was then separated by filtration and allowed to cool filtrate over time to give pure crystals of the desired 3,4-dihydropyrimidinones. The separated catalyst was suspended in ethanol $(1 \mathrm{~mL})$, for $30 \mathrm{~min}$ and filtered off, heated in an oven at $60^{\circ} \mathrm{C}$ for $1.5 \mathrm{~h}$ and then reused for successive runs.

\section{Conclusions}

In summary, we have developed an efficient, practical synthetic methodology for the preparation of 3,4dihydropyrimidin-2(1H)-ones using sulfonated pyromellitic dianhydride-functionalized MCM-41 (MCM-41- 
APS-PMDA-SO ${ }_{3} \mathrm{H}$ ), as a heterogeneous multifunctional hybrid catalyst, under solvent-free conditions. High catalytic performance, favored reusability of the newly introduced hybrid organosilica with negligible loss of its activity, compatibility with various functional groups and easy and quick isolation of the products are the main advantages of this procedure. Further works to expand and apply MCM-41APS-PMDA- $\mathrm{SO}_{3} \mathrm{H}$ nanomaterials in organic synthesis and transformation is ongoing in our laboratory and would be presented in due courses.

\section{Declarations}

\section{Acknowledgements}

We are grateful for the financial support from The Research Council of Iran University of Science and Technology (IUST), Tehran, Iran (Grant No 160/19108). We would also like to acknowledge the support of the Iran Nanotechnology Initiative Council (INIC).

\section{References}

1. Li, W. \& Fu, F. Incorporating MnFe2O4 onto the thiol-functionalized MCM-41 for effective capturing of $\mathrm{Sb}$ (III) in aqueous media. Microporous and Mesoporous Materials. 298, 110060 (2020).

2. Rout, L., Mohan, A., Thomas, A. M. \& Ha, C. S. Rational design of thermoresponsive functionalized MCM-41 and their decoration with bimetallic Ag-Pd nanoparticles for catalytic application. Microporous and Mesoporous Materials. 291, 109711 (2020).

3. Ramazani, Z., Elhamifar, D., Norouzi, M. \& Mirbagheri, R. Magnetic mesoporous MCM-41 supported boric acid: A novel, efficient and ecofriendly nanocomposite. Composites Part B: Engineering. 164, 10-17 (2019).

4. Björklund, S. \& Kocherbitov, V. Alcohols react with MCM-41 at room temperature and chemically modify mesoporous silica. Sci. Rep. 7, 9960 https://doi.org/10.1038/s41598-017-10090-x (2017).

5. Hajjami, M., Shiri, L. \& Jahanbakhshi, A. Zirconium oxide complex-functionalized MCM-41 nanostructure: an efficient and reusable mesoporous catalyst for oxidation of sulfides and oxidative coupling of thiols using hydrogen peroxide. Appl. Organomet. Chem. 29, 668-673 (2015).

6. Karthikeyan, G., Pandurangan, A. \& Heteropolyacid (H3PW12040) supported MCM-41: An efficient solid acid catalyst for the green synthesis of xanthenedione derivatives. Journal of Molecular Catalysis A: Chemical. 311, 36-45 (2009).

7. Mandal, M., Nagaraju, V., Sarma, B., Karunakar, G. \& Bania, K. K. Enantioselective Epoxidation of Styrene by Manganese Chiral Schiff Base Complexes Immobilized on MCM-41. ChemPlusChem. 80, 749-761 (2015).

8. Amolegbe, S. A. et al. Mesoporous silica nanocarriers encapsulated antimalarials with high therapeutic performance. Sci. Rep. 8, 3078 https://doi.org/10.1038/s41598-018-21351-8 (2018). 
9. Stewart, C. A., Finer, Y. \& Hatton, B. D. Drug self-assembly for synthesis of highly-loaded antimicrobial drug-silica particles. Sci. Rep. 8, 895 https://doi.org/10.1038/s41598-018-19166-8 (2018).

10. Shevtsov, M. A. et al. Zero-valent Fe confined mesoporous silica nanocarriers (Fe(0) @ MCM-41) for targeting experimental orthotopic glioma in rats. Sci. Rep. 6, 29247 https://doi.org/10.1038/srep29247 (2016).

11. Brezoiu, A. M. et al. Heteroatom modified MCM-41-silica carriers for Lomefloxacin delivery systems. Microporous and Mesoporous Materials. 275, 214-222 (2019).

12. Omar, H. et al. Impact of pore-walls ligand assembly on the biodegradation of mesoporous Organosilica nanoparticles for controlled drug delivery. ACS omega. 3, 5195-5201 (2018).

13. Qi, R. et al. Humidity sensors based on MCM-41/polypyrrole hybrid film via in-situ polymerization. Sensors and Actuators B: Chemical. 277, 584-590 (2018).

14. Yang, Y., Hu, J. \& He, J. Mesoporous Nano-Silica Serves as the Degradation Inhibitor in Polymer Dielectrics. Sci. Rep. 6, 28749 https://doi.org/10.1038/srep28749 (2016).

15. Macquarrie, D. J. \& Hu, W. in Sol-Gel Methods for Materials Processing. (eds Plinio Innocenzi, Yuriy L. Zub, \& Vadim G. Kessler)187-194(Springer Netherlands).

16. Nowicki, J., Jaroszewska, K., Nowakowska-Bogdan, E., Szmatoła, M. \& Iłowska, J. Synthesis of 2, 2, 4-trimethyl-1, 2-H-dihydroquinoline (TMQ) over selected organosulfonic acid silica catalysts:

Selectivity aspects. Molecular Catalysis. 454, 94-103 (2018).

17. Kuboňová, L. et al. Catalytic activity of cobalt grafted on ordered mesoporous silica materials in N2O decomposition and CO oxidation. Molecular Catalysis. 437, 57-72 (2017).

18. Sun, Z., Cui, G., Li, H., Tian, Y. \& Yan, S. Multifunctional dendritic mesoporous silica nanospheres loaded with silver nanoparticles as a highly active and recyclable heterogeneous catalyst. Colloids and Surfaces A: Physicochemical and Engineering Aspects. 489, 142-153 (2016).

19. Macquarrie, D. J. \& Mena Durán, C. J. in Sustainable Catalysis: Without Metals or Other Endangered Elements, Part 1 65-78(The Royal Society of Chemistry, 2016).

20. Viscardi, R., Barbarossa, V., Maggi, R. \& Pancrazzi, F. Effect of acidic MCM-41 mesoporous silica functionalized with sulfonic acid groups catalyst in conversion of methanol to dimethyl ether. Energy Reports. 6, 49-55 https://doi.org/10.1016/j.egyr.2020.10.042 (2020).

21. Martínez-Edo, G., Balmori, A., Pontón, I. \& Martí del Rio, A. \& Sánchez-García, D. Functionalized Ordered Mesoporous Silicas (MCM-41): Synthesis and Applications in Catalysis. Catalysts. 8, 617 (2018).

22. Rizzi, V. et al. Amino grafted MCM-41 as highly efficient and reversible ecofriendly adsorbent material for the Direct Blue removal from wastewater. Journal of Molecular Liquids. 273, 435-446 (2019).

23. Wilson, K. \& Lee, A. F. Catalyst design for biorefining. Philosophical Transactions of the Royal Society A: Mathematical, Physical and Engineering Sciences. 374, 20150081 https://doi.org/10.1098/rsta.2015.0081 (2016). 
24. Abu-Zied, B. M., Alam, M., Asiri, A. M., Schwieger, W. \& Rahman, M. M. Fabrication of 1, 2dichlorobenzene sensor based on mesoporous MCM-41 material. Colloids and Surfaces A: Physicochemical and Engineering Aspects. 562, 161-169 (2019).

25. Luque, R. \& Clark, J. H. Valorisation of food residues: waste to wealth using green chemical technologies. Sustain. Chem. Process. 1, 10 https://doi.org/10.1186/2043-7129-1-10 (2013).

26. Ghorbani-Choghamarani, A., Tahmasbi, B., Hudson, R. H. \& Heidari, A. Supported organometallic palladium catalyst into mesoporous channels of magnetic MCM-41 nanoparticles for phosphine-free CC coupling reactions. Microporous and Mesoporous Materials. 284, 366-377 (2019).

27. Iwanami, K., Seo, H., Choi, J. C., Sakakura, T. \& Yasuda, H. Al-MCM-41 catalyzed three-component Strecker-type synthesis of a-aminonitriles. Tetrahedron. 66, 1898-1901 https://doi.org/10.1016/j.tet.2010.01.001 (2010).

28. Karami, S., Dekamin, M. G., Valiey, E. \& Shakib, P. DABA MNPs: a new and efficient magnetic bifunctional nanocatalyst for the green synthesis of biologically active pyrano[2,3-c]pyrazole and benzylpyrazolyl coumarin derivatives. New Journal of Chemistry. 44, 13952-13961 https://doi.org/10.1039/D0NJ02666B (2020).

29. Dekamin, M. G., Mokhtari, Z. \& Karimi, Z. Nano-ordered B-MCM-41: An efficient and recoverable solid acid catalyst for three-component Strecker reaction of carbonyl compounds, amines and TMSCN. Scientia Iranica. 18, 1356-1364 https://doi.org/10.1016/j.scient.2011.11.005 (2011).

30. Yaghoubi, A., Dekamin, M. G. \& Karimi, B. Propylsulfonic Acid-Anchored Isocyanurate-Based Periodic Mesoporous Organosilica (PMO-ICS-PrSO3H): A Highly Efficient and Recoverable Nanoporous Catalyst for the One-Pot Synthesis of Substituted Polyhydroquinolines. Catal. Lett. 147, 2656-2663 https://doi.org/10.1007/s10562-017-2159-5 (2017).

31. Yaghoubi, A., Dekamin, M. G., Arefi, E. \& Karimi, B. Propylsulfonic acid-anchored isocyanurate-based periodic mesoporous organosilica (PMO-ICS-Pr-SO3H): A new and highly efficient recoverable nanoporous catalyst for the one-pot synthesis of bis(indolyl)methane derivatives. Journal of Colloid and Interface Science. 505, 956-963 https://doi.org/10.1016/j.jcis.2017.06.055 (2017).

32. Akbari, A., Dekamin, M. G., Yaghoubi, A. \& Naimi-Jamal, M. R. Novel magnetic propylsulfonic acidanchored isocyanurate-based periodic mesoporous organosilica (Iron oxide@PMO-ICS-PrSO3H) as a highly efficient and reusable nanoreactor for the sustainable synthesis of imidazopyrimidine derivatives. Sci. Rep. 10, 10646 https://doi.org/10.1038/s41598-020-67592-4 (2020).

33. Dekamin, M. G. \& Mokhtari, Z. Highly efficient and convenient Strecker reaction of carbonyl compounds and amines with TMSCN catalyzed by MCM-41 anchored sulfonic acid as a recoverable catalyst. Tetrahedron. 68, 922-930 (2012).

34. Choudhary, D., Paul, S., Gupta, R. \& Clark, J. H. Catalytic properties of several palladium complexes covalently anchored onto silica for the aerobic oxidation of alcohols. Green Chem. 8, 479-482 https://doi.org/10.1039/B601363E (2006).

35. Gupta, P., Kour, M., Paul, S. \& Clark, J. H. Ionic liquid coated sulfonated carbon/silica composites: novel heterogeneous catalysts for organic syntheses in water. RSC Advances. 4, 7461-7470 
https://doi.org/10.1039/C3RA45229H (2014).

36. Martins, M. A., Frizzo, C. P., Moreira, D. N., Buriol, L. \& Machado, P. Solvent-free heterocyclic synthesis. Chemical reviews. 109, 4140-4182 (2009).

37. Gawande, M. B., Bonifácio, V. D. B., Luque, R., Branco, P. S. \& Varma, R. S. Solvent-Free and CatalystsFree Chemistry: A Benign Pathway to Sustainability. 7,24-44, doi:https://doi.org/10.1002/cssc.201300485 (2014).

38. Kaur, R., Chaudhary, S., Kumar, K., Gupta, M. K. \& Rawal, R. K. Recent synthetic and medicinal perspectives of dihydropyrimidinones: A review. European journal of medicinal chemistry. 132, 108134 (2017).

39. Dömling, A., Wang, W. \& Wang, K. Chemistry and Biology Of Multicomponent Reactions. Chem. Rev. 112, 3083-3135 https://doi.org/10.1021/cr100233r (2012).

40. Dekamin, M. G. \& Eslami, M. Highly efficient organocatalytic synthesis of diverse and densely functionalized 2-amino-3-cyano-4H-pyrans under mechanochemical ball milling. Green Chem. 16, 4914-4921 https://doi.org/10.1039/C4GC00411F (2014).

41. Dekamin, M. G., Azimoshan, M. \& Ramezani, L. Chitosan: a highly efficient renewable and recoverable bio-polymer catalyst for the expeditious synthesis of a-amino nitriles and imines under mild conditions. Green Chem. 15, 811-820 https://doi.org/10.1039/C3GC36901C (2013).

42. Dekamin, M. G., Alikhani, M., Emami, A., Ghafuri, H. \& Javanshir, S. An efficient catalyst- and solventfree method for the synthesis of medicinally important dihydropyrano[2,3-c]pyrazole derivatives using ball milling technique. Journal of the Iranian Chemical Society. 13, 591-596 https://doi.org/10.1007/s13738-015-0793-7 (2016).

43. Matos, L. H. S., Masson, F. T. \& Simeoni, L. A. \& Homem-de-Mello, M. Biological activity of dihydropyrimidinone (DHPM) derivatives: A systematic review. European Journal of Medicinal Chemistry. 143, 1779-1789 (2018).

44. Fard, M. A. D., Ghafuri, H. \& Rashidizadeh, A. Sulfonated highly ordered mesoporous graphitic carbon nitride as a super active heterogeneous solid acid catalyst for Biginelli reaction. Microporous and Mesoporous Materials. 274, 83-93 (2019).

45. Elhamifar, D., Hosseinpoor, F., Karimi, B. \& Hajati, S. Ionic liquid-based ordered mesoporous organosilica-supported copper as a novel and efficient nanocatalyst for the one-pot synthesis of Biginelli products. Microporous and Mesoporous Materials. 204, 269-275 (2015).

46. Sharma, V., Chitranshi, N. \& Agarwal, A. K. Significance and biological importance of pyrimidine in the microbial world. International journal of medicinal chemistry2014 (2014).

47. Wan, J. P. \& Liu, Y. Synthesis of dihydropyrimidinones and thiones by multicomponent reactions: strategies beyond the classical Biginelli reaction. Synthesis 2010, 3943-3953 (2010).

48. Heravi, M. M., Asadi, S. \& Lashkariani, B. M. Recent progress in asymmetric Biginelli reaction. Molecular diversity. 17, 389-407 (2013).

49. Huang, Y., Yang, F. \& Zhu, C. Biginelli Reaction Using a New Chiral Ytterbium Catalyst. Synfacts. 2006, 0132-0132 (2006). 
50. Jadhav, C. K. et al. Efficient Rapid Access to Biginelli for the Multicomponent Synthesis of 1, 2, 3, 4Tetrahydropyrimidines in Room-Temperature Diisopropyl Ethyl Ammonium Acetate. ACS omega. 4, 22313-22324 (2019).

51. Doustkhah, E. et al. Development of Sulfonic-Acid-Functionalized Mesoporous Materials: Synthesis and Catalytic Applications. Chemistry-A European Journal. 25, 1614-1635 (2019).

52. Pramanik, M. \& Bhaumik, A. Phosphonic acid functionalized ordered mesoporous material: a new and ecofriendly catalyst for one-pot multicomponent Biginelli reaction under solvent-free conditions. ACS applied materials \& interfaces. 6, 933-941 (2014).

53. Vekariya, R. H., Prajapati, N. P. \& Patel, H. D. MCM-41-anchored sulfonic acid (MCM-41-SO3H): An efficient heterogeneous catalyst for green organic synthesis. Synth. Commun. 46, 1713-1734 (2016).

54. Dekamin, M. G., Mehdipoor, F. \& Yaghoubi, A. 1,3,5-Tris(2-hydroxyethyl)isocyanurate functionalized graphene oxide: a novel and efficient nanocatalyst for the one-pot synthesis of 3,4-dihydropyrimidin2(1H)-ones. New Journal of Chemistry. 41, 6893-6901 https://doi.org/10.1039/C7NJ00632B (2017).

55. Alirezvani, Z., Dekamin, M. G., Davoodi, F., Valiey, E. \& Melamine-Functionalized Chitosan A New BioBased Reusable Bifunctional Organocatalyst for the Synthesis of Cyanocinnamonitrile Intermediates and Densely Functionalized Nicotinonitrile Derivatives. ChemistrySelect. 3, 10450-10463 (2018).

56. Alirezvani, Z., Dekamin, M. G. \& Valiey, E. Cu (II) and magnetite nanoparticles decorated melaminefunctionalized chitosan: A synergistic multifunctional catalyst for sustainable cascade oxidation of benzyl alcohols/Knoevenagel condensation. Scientific reports. 9, 1-12 (2019).

57. Alirezvani, Z., Dekamin, M. G. \& Valiey, E. New Hydrogen-Bond-Enriched 1, 3, 5-Tris (2-hydroxyethyl) Isocyanurate Covalently Functionalized MCM-41: An Efficient and Recoverable Hybrid Catalyst for Convenient Synthesis of Acridinedione Derivatives. ACS omega. 4, 20618-20633 (2019).

58. Banakar, S. H., Dekamin, M. G. \& Yaghoubi, A. Selective and highly efficient synthesis of xanthenedione or tetraketone derivatives catalyzed by $\mathrm{ZnO}$ nanorod-decorated graphene oxide. New Journal of Chemistry. 42, 14246-14262 (2018).

59. Dekamin, M. G., Arefi, E. \& Yaghoubi, A. Isocyanurate-based periodic mesoporous organosilica (PMOICS): a highly efficient and recoverable nanocatalyst for the one-pot synthesis of substituted imidazoles and benzimidazoles. RSC advances. 6, 86982-86988 (2016).

60. Valiey, E., Dekamin, M. G. \& Alirezvani, Z. Melamine-modified chitosan materials: An efficient and recyclable bifunctional organocatalyst for green synthesis of densely functionalized bioactive dihydropyrano [2, 3-c] pyrazole and benzylpyrazolyl coumarin derivatives. International journal of biological macromolecules. 129, 407-421 (2019).

61. Bharathi, M., Indira, S., Vinoth, G. \& Bharathi, K. S. Immobilized Ni-Schiff-base metal complex on MCM-41 as a heterogeneous catalyst for the green synthesis of benzimidazole derivatives using glycerol as a solvent. Journal of Porous Materials. 26, 1377-1390 (2019).

62. Romanelli, G. P., Sathicq, A. G., Autino, J. C., Baronetti, G. \& Thomas, H. J. Solvent-Free Approach to 3, 4-Dihydropyrimidin-2 (1 H)-(thio) ones: Biginelli Reaction Catalyzed by a Wells-Dawson Reusable 
Heteropolyacid. Synth. Commun. 37, 3907-3916 (2007).

63. Patel, H. A., Sawant, A. M., Rao, V. J., Patel, A. L. \& Bedekar, A. V. Polyaniline supported FeCl 3: an effective heterogeneous catalyst for Biginelli reaction. Catal. Lett. 147, 2306-2312 (2017).

64. Hosseini, M. M., Kolvari, E., Koukabi, N., Ziyaei, M. \& Zolfigol, M. A. Zirconia sulfuric acid: an efficient heterogeneous catalyst for the one-pot synthesis of 3, 4-dihydropyrimidinones under solvent-free conditions. Catal. Lett. 146, 1040-1049 (2016).

65. Safaei-Ghomi, J., Tavazo, M. \& Mahdavinia, G. H. Ultrasound promoted one-pot synthesis of 3, 4dihydropyrimidin-2 $(1 \mathrm{H})$-ones/thiones using dendrimer-attached phosphotungstic acid nanoparticles immobilized on nanosilica. Ultrasonics sonochemistry. 40, 230-237 (2018).

66. Li, W., Zhou, G. \& Zhang, P. One-pot synthesis of dihydropyrimidiones via environmentally friendly enzyme-catalyzed Biginelli reaction. Heterocycles. 83, 2067-2077 (2011).

67. Ghafuri, H. \& Talebi, M. Water-soluble phosphated graphene: preparation, characterization, catalytic reactivity, and adsorption property. Ind. Eng. Chem. Res. 55, 2970-2982 (2016).

68. Wang, D. C., Guo, H. M. \& Qu, G. R. Efficient, green, solvent-free synthesis of 3, 4-dihydropyrimidin-2 $(1 \mathrm{H})$-ones via Biginelli reaction catalyzed by $\mathrm{Cu}(\mathrm{NO} 3) 2 \cdot 3 \mathrm{H} 2 \mathrm{O}$. Synthetic Communications ${ }^{\circledR} .40$, 1115-1122 (2010).

69. Kolvari, E., Koukabi, N., Hosseini, M. M., Vahidian, M. \& Ghobadi, E. Nano-ZrO 2 sulfuric acid: a heterogeneous solid acid nano catalyst for Biginelli reaction under solvent free conditions. RSC advances. 6, 7419-7425 (2016).

70. Khiratkar, A. G., Muskawar, P. N. \& Bhagat, P. R. Polymer-supported benzimidazolium based ionic liquid: an efficient and reusable Brønsted acid catalyst for Biginelli reaction. RSC advances. 6, 105087-105093 (2016).

71. Zamani, F. \& Izadi, E. Synthesis and characterization of sulfonated-phenylacetic acid coated Fe304 nanoparticles as a novel acid magnetic catalyst for Biginelli reaction. Catal Commun. 42, 104-108 (2013).

72. Salehi, P., Dabiri, M. \& Zolfigol, M. A. Efficient synthesis of 3, 4-dihydropyrimidin-2 (1H)-ones over silica sulfuric acid as a reusable catalyst under solvent-free conditions. Heterocycles. 60, 2435-2440 (2003).

73. Tamaddon, F. \& Moradi, S. Controllable selectivity in Biginelli and Hantzsch reactions using nanoZnO as a structure base catalyst. Journal of Molecular Catalysis A: Chemical. 370, 117-122 (2013).

74. KÜÇÜKISLAMOĞLU, M., Zengin, B. E. Å. O. L. U. K. Å., Arslan, M. \& NEBiOĞLU, M. An efficient one-pot synthesis of dihydropyrimidinones catalyzed by zirconium hydrogen phosphate under solvent-free conditions. Turkish Journal of Chemistry. 34, 411-416 (2010).

\section{Tables}

Due to technical limitations, tables are only available as a download in the Supplemental Files section. 


\section{Figures}

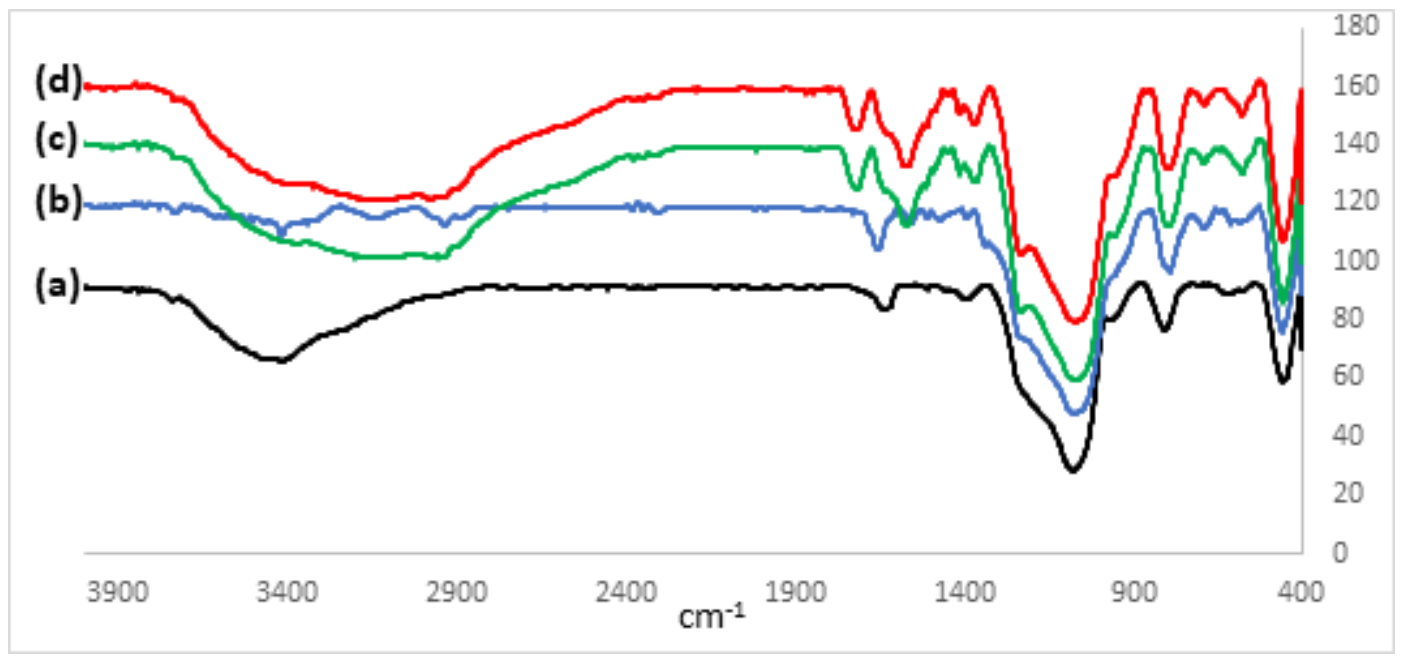

Figure 1

FTIR spectra of the MCM-41 (a), MCM-41-APS (b) MCM-41-APS-PMDA (c) and MCM-41-APS-PMDA-SO3H (d) (1)
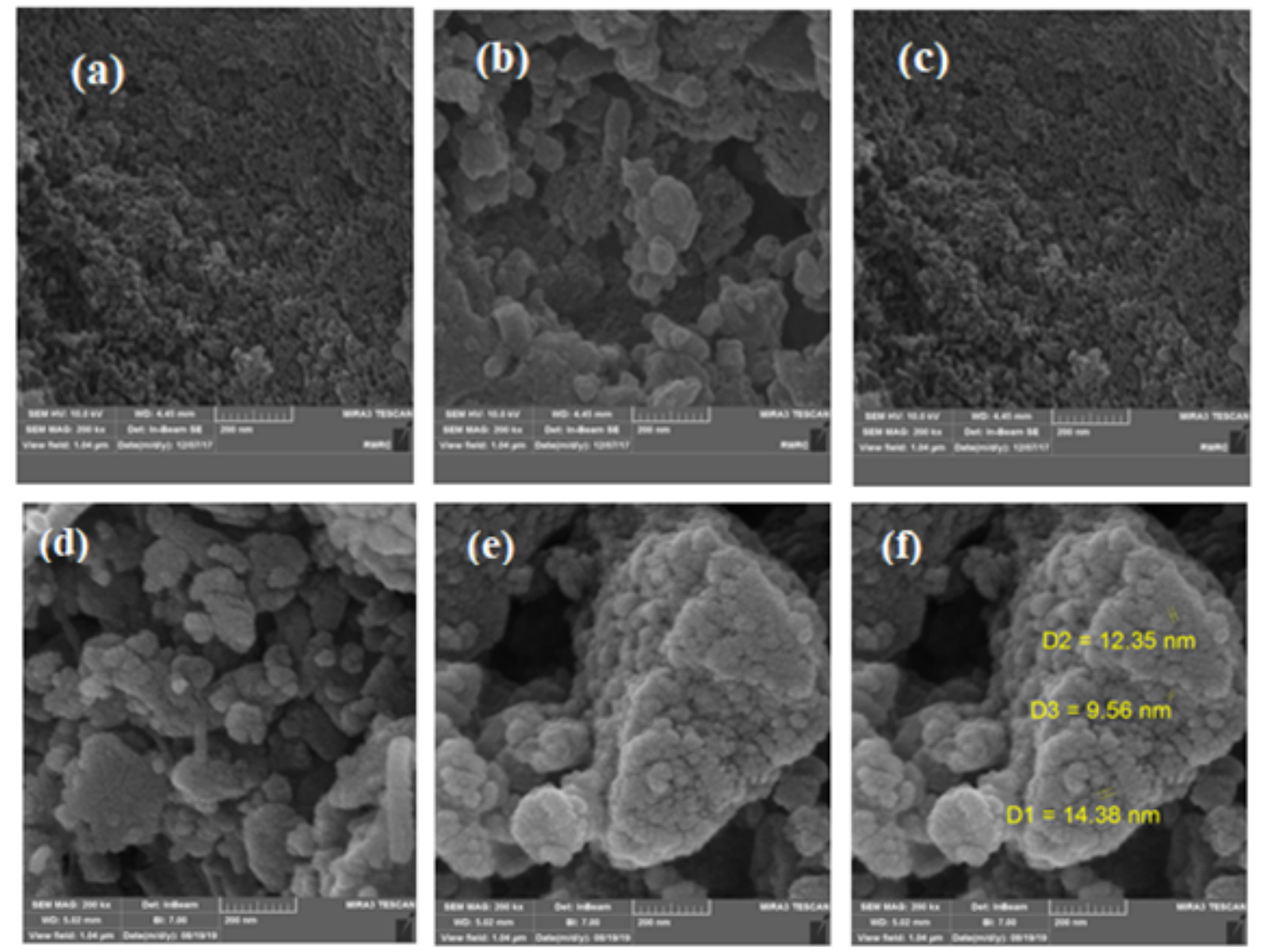

Figure 2 
FESEM images of the MCM-41 ( $a, b$ and $c)$ and the MCM-41-APS-PMDA-SO3H ( $1, d, e$ and $f)$ materials $(b)$ scale $200 \mathrm{~nm}$

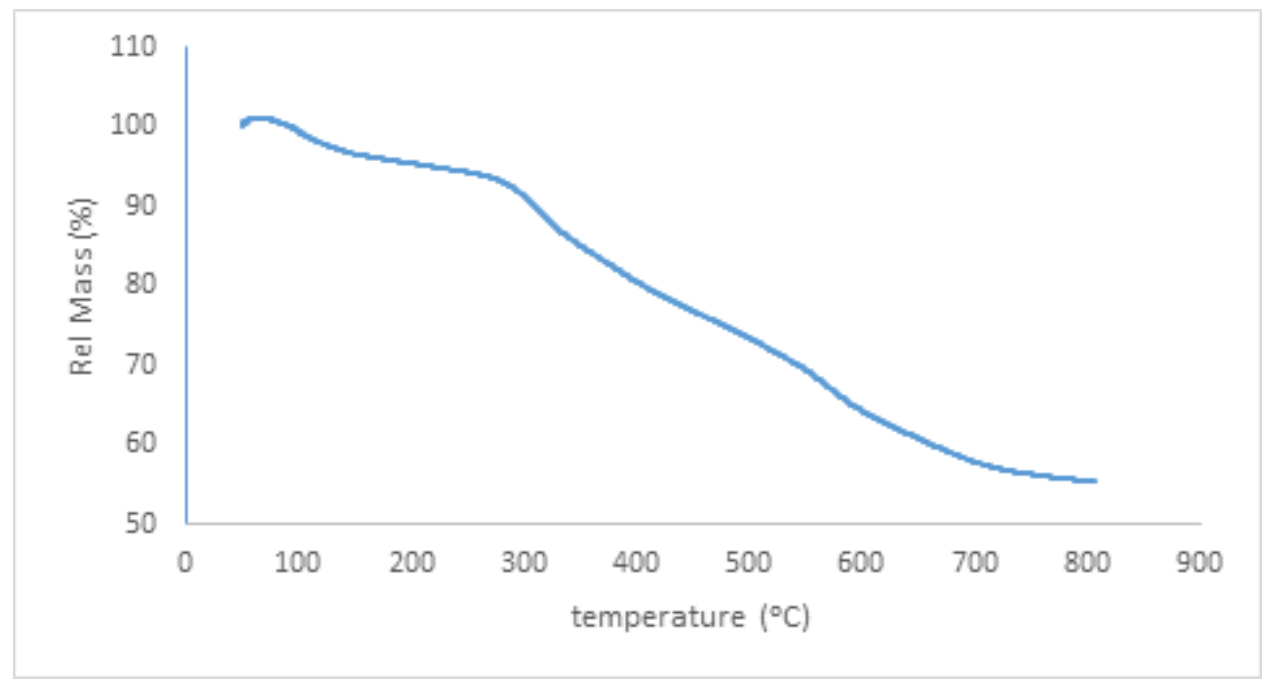

\section{Figure 3}

TGA analysis of the MCM-41-APS-PMDA-SO3H (1) materials.

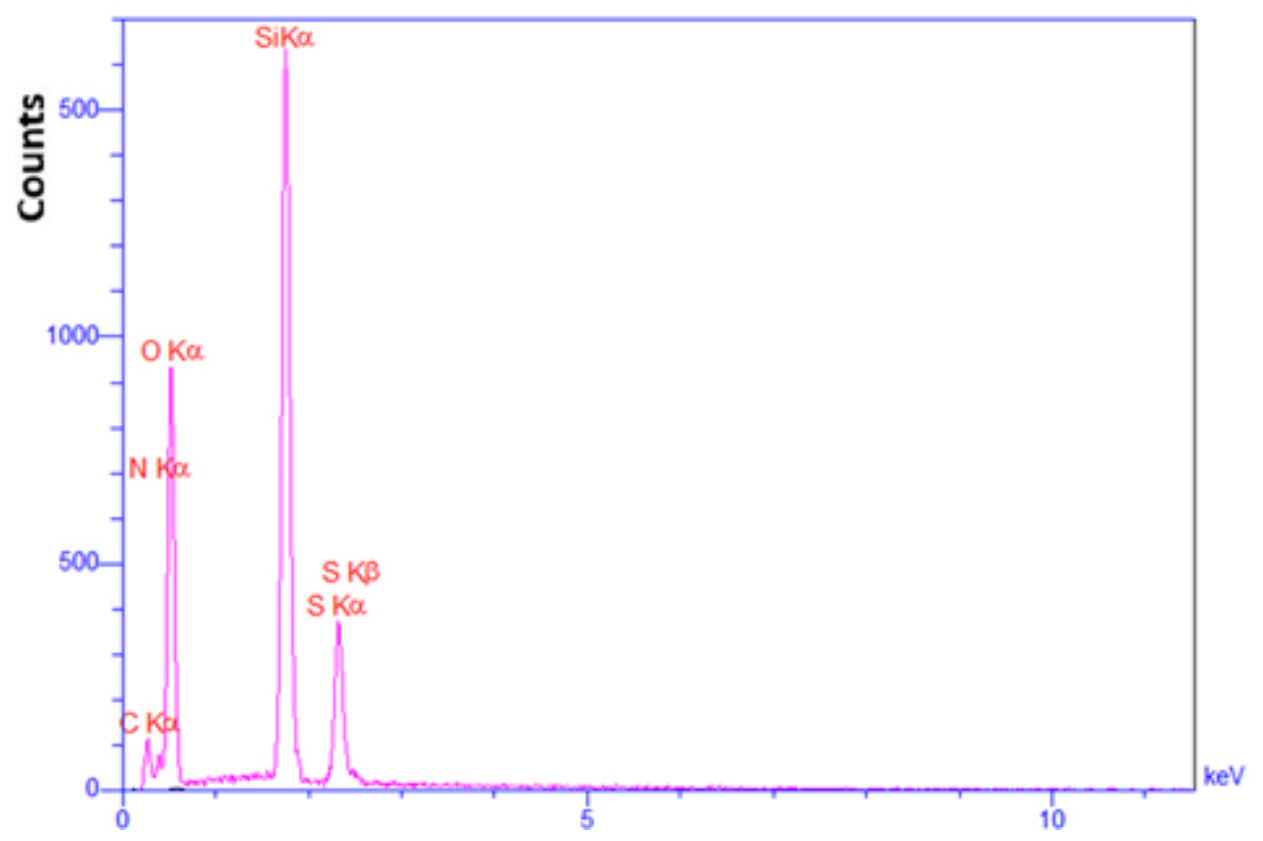

Figure 4

EDX pattern of MCM-41-APS-PMDA-SO3H (1) materials. 

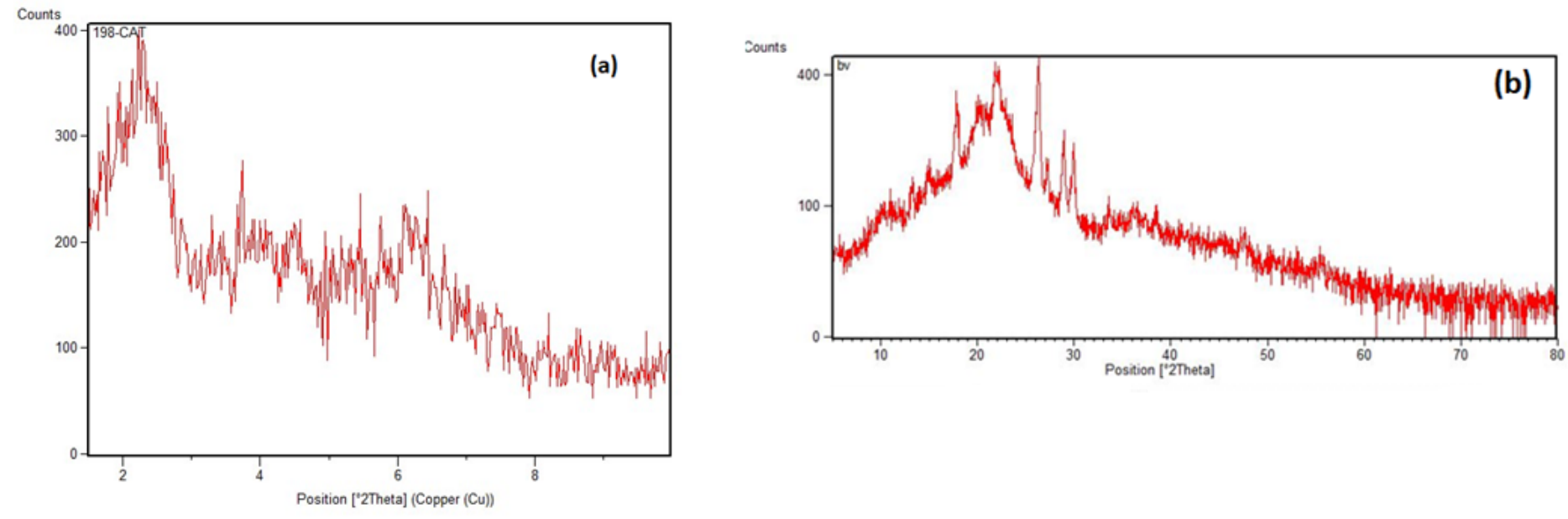

\section{Figure 5}

XRD patterns of a) MCM-41 and b) MCM-41-APS-PMDA-SO3H (1).

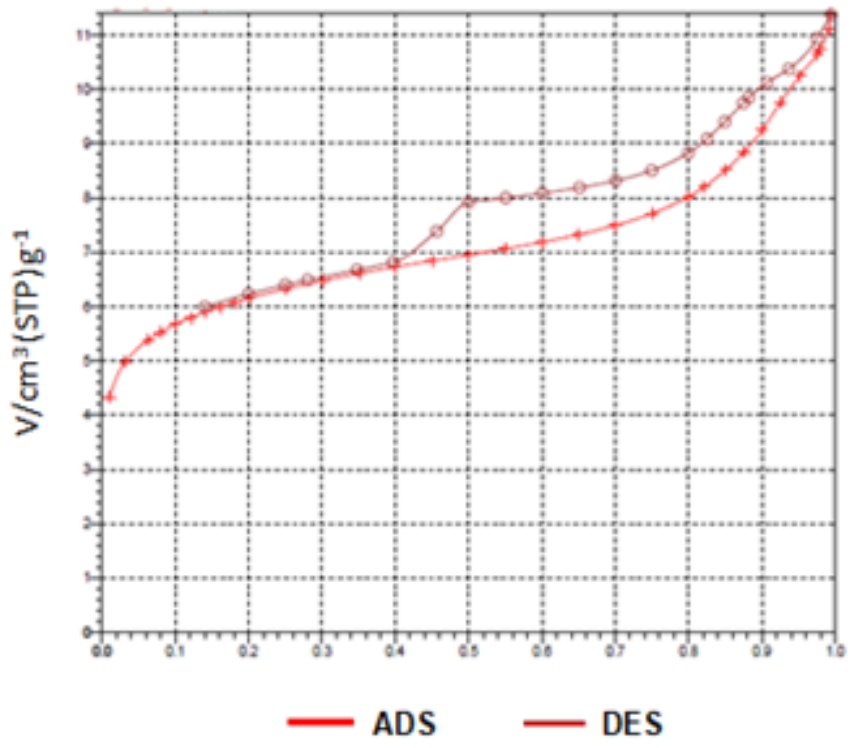

\begin{tabular}{|c|c|c|c|}
\hline Samples & BET surface area $\mathrm{m}^{2} / \mathrm{g}$ & $\begin{array}{c}\text { Total pore Vol. }\left(\mathrm{cm}^{3} / \mathrm{g}\right) \\
\left(\mathrm{P}^{\circ}: 0 / 062\right)\end{array}$ & Pore size $(\mathrm{nm})$ \\
\hline MCM-41 & 926.25 & 1.09 & 4.07 \\
\hline $\begin{array}{l}\text { MCM-41-APS-PMDA- } \\
\text { SO3H }\end{array}$ & 477.47 & 0.11 & 5.36 \\
\hline
\end{tabular}

Figure 6

Adsorption/desorption isotherm of the MCM-41-APS-PMDA-SO3H (1). 


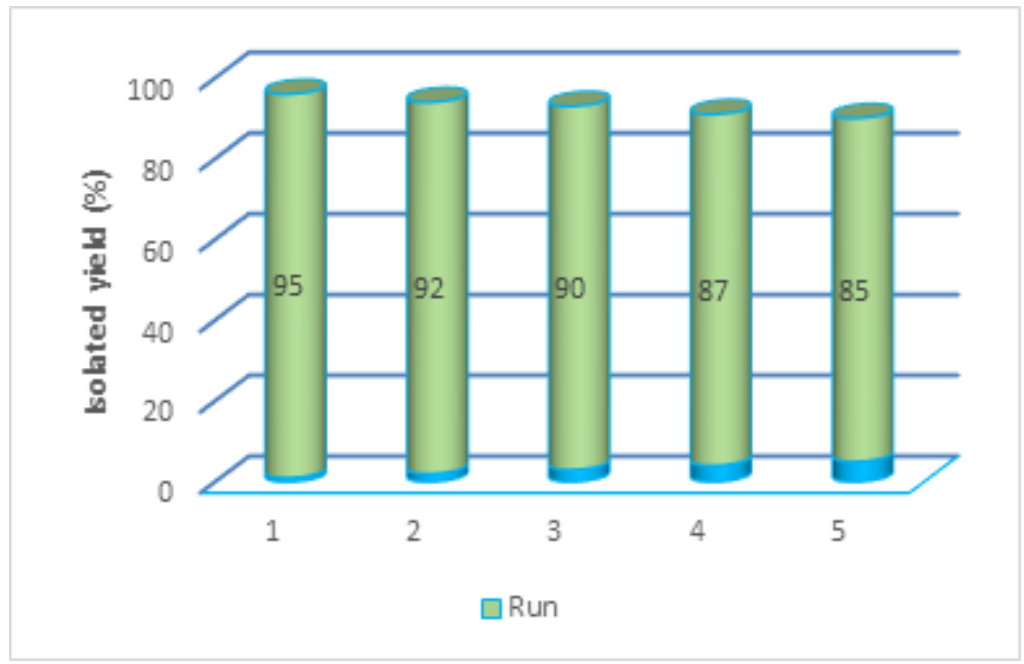

Figure 7

Reuse of the heterogeneous acidic nanocatalyst MCM-41-APS-PMDA-SO3H (1) for the synthesis of 5 a. 


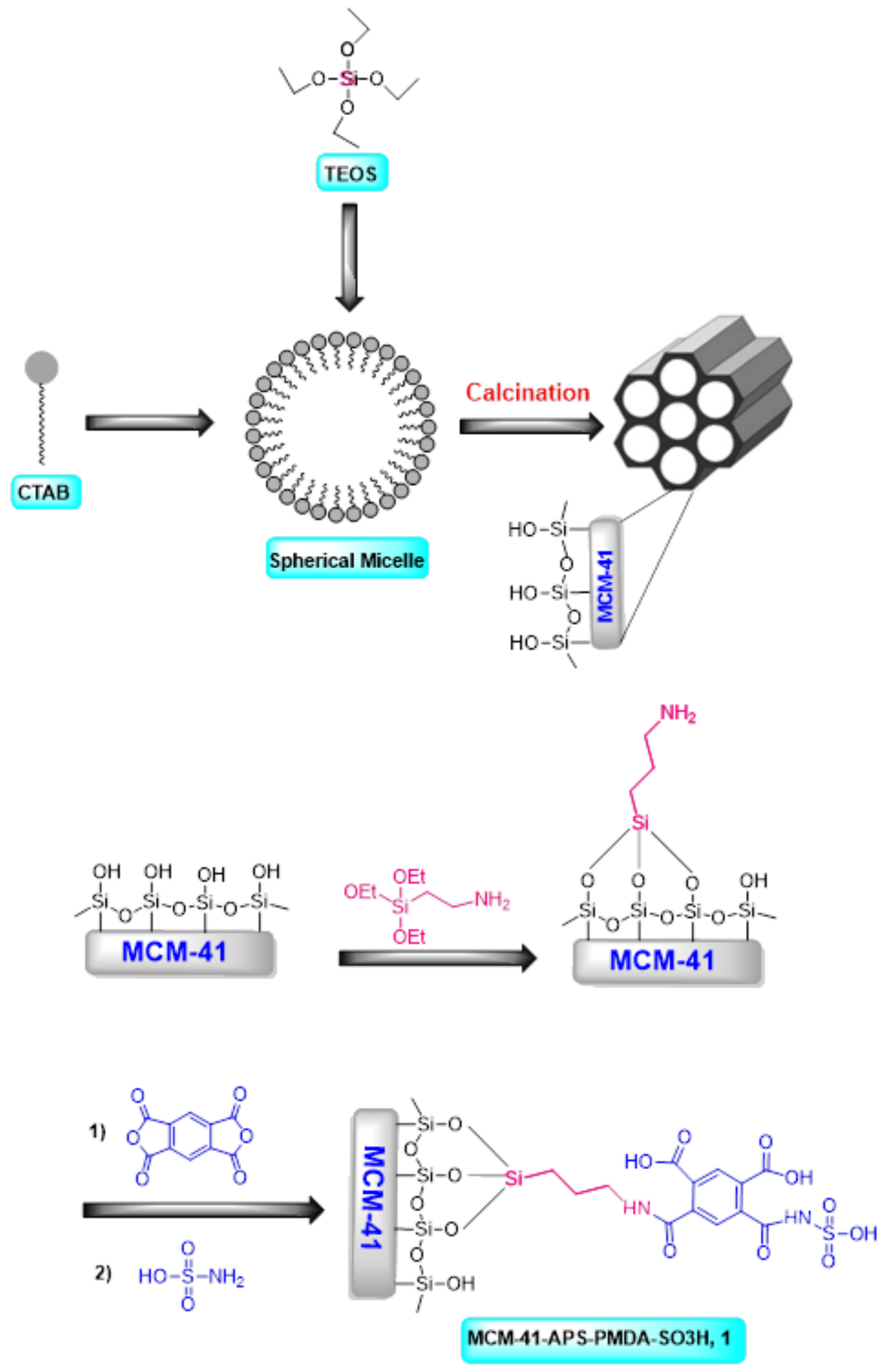

Figure 8

Schematic preparation of sulfonated pyromellitic dianhydride-aminopropyl silane-functionalized MCM-41 (MCM-41-APS-PMDA-SO3H, 1). 


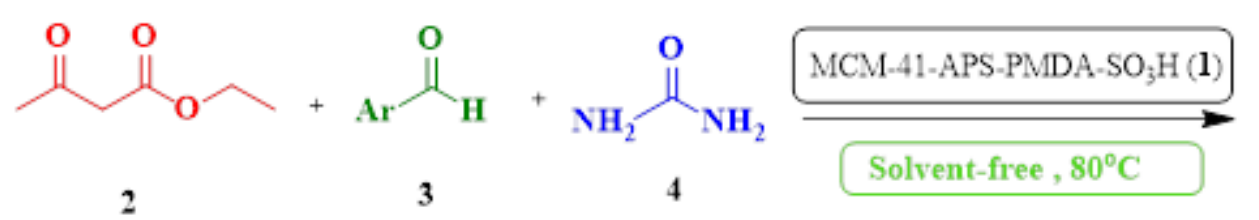

Figure 9

The three-components condensation of ethyl acetoacetate (2), aldehydes (3), urea (4) catalyzed by sulfonated pyromellitic dianhydride-aminopropyl silane-functionalized MCM-41 (MCM-41-APS-PMDA$\mathrm{SO} 3 \mathrm{H}, 1)$.
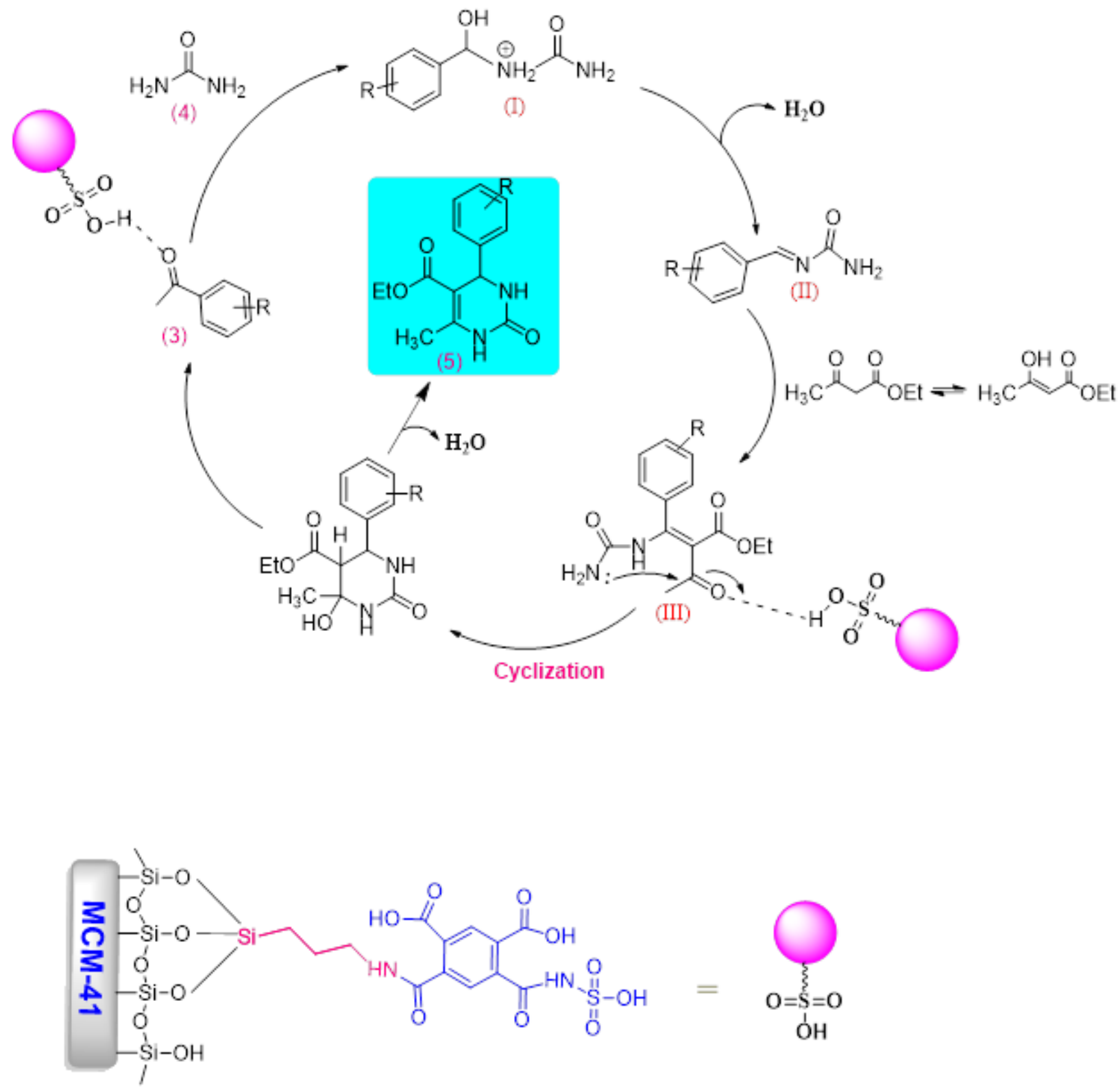

MCM-41-APS-PMDA-SO3H, 1

Figure 10 
Proposed mechanism for the synthesis of 3,4-dihydropyrimidin-2(1H)-ones catalyzed by sulfonated pyromellitic dianhydride-aminopropyl silane-functionalized MCM-41 (MCM-41-APS-PMDA-SO3H.

\section{Supplementary Files}

This is a list of supplementary files associated with this preprint. Click to download.

- ElectronicSupplementaryScientificReports3.docx

- Tables.docx 